\title{
Do burglar alarms increase burglary risk? A counter-intuitive finding and possible explanations
}

Nick Tilley ${ }^{\mathrm{a}, *}$, Rebecca Thompson ${ }^{\mathrm{b}}$, Graham Farrell ${ }^{\mathrm{c}}$, Louise Grove ${ }^{\mathrm{d}}$ and Andromachi Tseloni ${ }^{\mathrm{d}}$

${ }^{\mathrm{a} D e p a r t m e n t}$ of Security and Crime Science, University College London, 35 Tavistock Square, London, WC1H 9EZ, UK.

bInstitute for Public Safety, Crime and Justice, The University of Northampton, Park Campus, Boughton Green Road, Northampton, NN2 7AL, UK.

'School of Criminology, Simon Fraser University, 8888 University Drive, Burnaby, British Columbia, Canada V5A 156.

'Department of Social Sciences, Loughborough University, Loughborough Leicestershire LE11 3TU, UK.

*Corresponding author.

Abstract Burglar alarms are widely used as a means to try to reduce the risk of domestic burglary. Previous research has suggested that some burglars are deterred by alarms and that they are therefore effective. Using multiple sweeps of the Crime Survey for England and Wales, the research reported here sought to corroborate these findings. It finds that alarms have become associated with increased rather than decreased risk of burglary with entry. This counter-intuitive finding needs to be treated cautiously. A series of hypotheses that might explain it are outlined.

Crime Prevention and Community Safety (2015) 17, 1-19. doi:10.1057/cpcs.2014.17

Keywords: intruder alarms; domestic burglary risk; situational crime prevention The online version of this article is available Open Access

\section{Introduction}

ecurity devices generally help to prevent domestic burglary (Tseloni et al, 2014). For the most part, the more security devices fitted to a property the lower the risk of burglary. But this is not necessarily 
always the case. This article reports some intriguing findings based on data from the Crime Survey for England and Wales (CSEW), which suggest that the addition of burglar alarms may be counter-productive. The analysis reported here attempts to isolate the 'additive' or 'specific' impact of an alarm within a potentially wider set of security options to overcome the limitation of previous studies, which in general do not identify any alarm effects on their own.

The discussion that follows begins with a brief account of the origins of and growth in the use of alarms as domestic burglary prevention devices. An overview of the previous literature touching on the effectiveness of burglar alarms comes next. The data and methodology used for the current study are presented thereafter, followed by a discussion of the results. A series of possible hypotheses that might explain the results is then outlined, including comments on their plausibility and an outline of what would be needed to test them. Further research to corroborate or falsify the findings reported here and to explain the patterns if they are confirmed is important for householders, the security industry, insurance companies and those public services that advise on, or in some cases subsidise, security upgrades.

\section{The Development of Alarms}

Mechanically operated alarm systems (with pull wires) go back to the 1700s in England. The first patent for an electric burglar alarm was granted in the United States to Pope on 21 June 1853 'for the purpose of giving an alarm in case of burglarious or other attempts to enter' a domestic property. This led to the establishment of what became the Holmes Electric Protection Company, which installed and operated electric burglar alarm systems and later operated a private police force to respond to alarms (uv201.com, n.d.). In 1895, Tomney was granted a patent for a different version of burglar alarm, featuring safeguards against tampering. The American District Telegraph Company (ADT) eventually took over. ADT divided New York into small blocks, each covered by its own monitoring station (Donnelly, 1992). ADT are now major providers of alarms in the United Kingdom.

Since the nineteenth century there have been extensive further developments in alarm technology, with motion detectors, linked video surveillance, sensors, wireless systems and systems that will call a mobile phone if intrusion is detected. The price of alarms also fell precipitously in the 1990s, making installation relatively cheap and affordable by the many rather than the few.

The Association of British Insurance Surveyors was established in 1953. Given their then high cost, the advice in 1962 was that burglar alarms should be used where other forms of physical security were inadequate and that they should be installed where risks were highest (Bugg, 1962). Currently there are systems approved by the British Security Industry Association or the National 
Security Inspectorate or the Security Systems and Alarms Inspection Board, but not all alarms that are installed meet these standards.

In practice, alarm systems vary widely in sophistication and cost. In 2005, it was reported that do-it-yourself systems could be installed for around $£ 150-200$. A professionally fitted system that rings internally and externally would cost around $£ 500$ with $£ 60-100$ a year for maintenance. A monitored system would cost around $£ 800-900$ for installation, plus $£ 200-300$ per annum for monitoring and maintenance (and requires police approval). Dummy alarms cost $£ 7.50-8.00$ (Papworth and Collinson, 2005).

Figure 1 shows the growth in the percentage of domestic properties covered by burglar alarms as estimated across sweeps of the CSEW from 1992 to 2012. Numbers rose from 13 per cent in 1992 to just under 30 per cent in 2009/2010, before falling back slightly in 2011/2012.

False alarms have comprised a major problem for the police (Litton and Pease, 1984; LeBeau and Vincent, 1997; Cahalane, 2001; Sampson, 2011). In the United Kingdom, police attend bells-only incidents - with unmonitored systems - only if there is independent corroboration that a burglary is taking place. False alarm rates have run at roughly 94-98 per cent; for example, 97.77 per cent were false in Charlotte in 1990, 98 per cent in Baltimore in 1994 and 98.33 per cent in Chicago in 1994 (LeBeau and Vincent, 1997; Sampson, 2002). Repeated false alarms will eventually lead to withdrawal of police response in the United Kingdom (ACPO, 2006). Perhaps as a response to similar problems, in the United States alarm permits have in principle come to be required very widely, with escalating fines for false alarms (LeBeau and Vincent, 1997; Sampson, 2011).

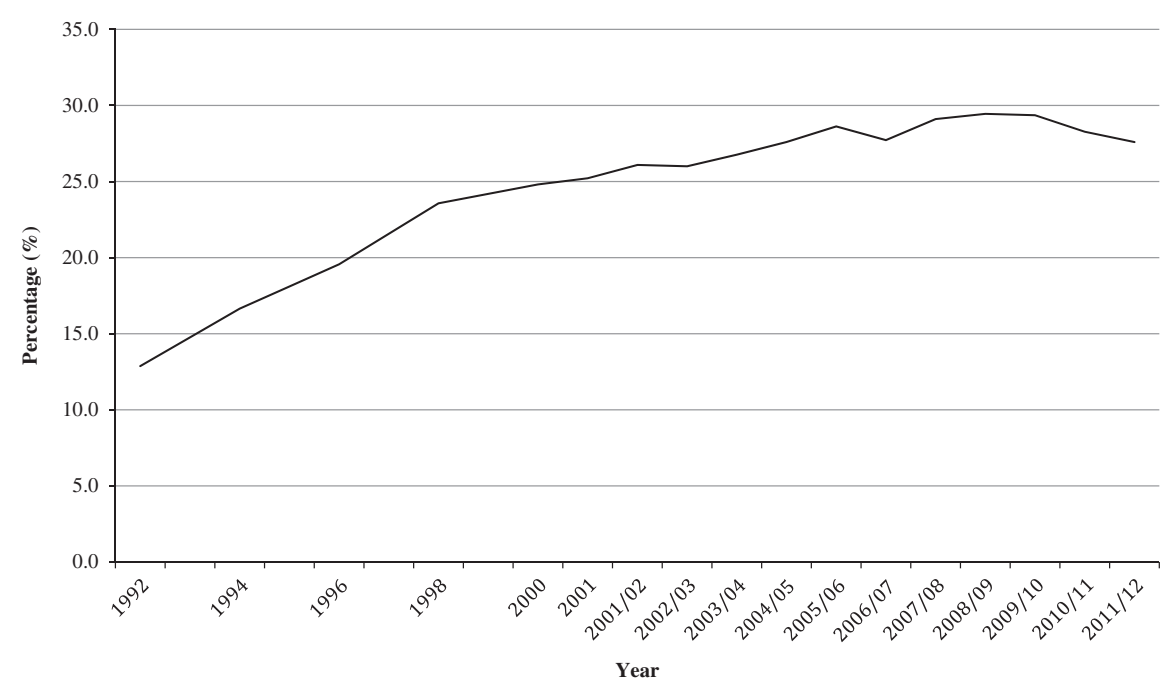

Figure 1: Proportion (in per cent) of households with a burglar alarm by CSEW sweep, 1992-2011/2012. 
There are clearly costs in false alarms. One direct cost includes the amount of time the police can waste on them. For example, in Chicago in 1995 it was estimated that attending false alarms accounted for the time of the equivalent of 195 full time officers (LeBeau and Vincent, 1997, p. 291). In Charlotte in 1990, of 38622 alarm activations only 1083 were not false, with 762 for burglary. The non-false alarms led to just 117 on-scene arrests, with 81 for burglary (Lebeau and Vincent, 1997, pp. 292-293). From the police point of view, therefore, attending an alarm in Charlotte offered only a 1 in 330 chance of making an arrest for a crime in progress. From a burglar's point of view the chance of an arrest was 1 in 9.5 when alarms automatically elicited a police response.

A second, social cost relates to the noise nuisance for neighbours. There have been a variety of responses to the problem of false alarms. These have included publication of standards for alarm systems and the requirement that these be met for police recognition, the need for permits for alarms to be installed, the demand for corroboration that an offence is in progress for a police response to it to be given, fines for false alarms, degraded or non-response for repeated false alarms and a statutory maximum period for an alarm to sound.

\section{Previous Research Relating to Burglar Alarm Effectiveness}

Alarms make common sense, and have high surface plausibility as devices to prevent burglary. Unlike door locks, shutters, window locks or grilles, however, they do not create a physical obstacle to burglary. Moreover, they do not make approaches to the target property more risky as would be the case with external lights or CCTV. Nor do they lead prospective burglars to believe that the property is occupied and hence that they may encounter someone who will interrupt their crime. Instead, alarms work on the assumption that potential burglars will believe that a neighbour, security guard or police officer will be summoned quickly and hence increase the risk that they will be apprehended.

Several different methods have been used in research touching on the effectiveness of alarms in preventing burglary. One has involved interviewing offenders, either in prison or in the community. A second has involved examining police records of offences. A third has involved victimisation surveys that ask respondents about the security devices installed at the time of the offence.

Incarcerated offenders clearly comprise a captive source for a sample of experienced burglars and have been used in research attempting to find the cues that lead certain properties to be selected and others to be avoided. Maguire and Bennett (1982) interviewed 40 incarcerated persistent burglars. They found that they chose familiar areas and were most put off by signs of occupancy and by lack of cover from walls, trees, shrubbery or other buildings. Bennett and Wright (1984) interviewed a sample of 300 incarcerated burglars and found that surveillability and occupancy were important in decision making 
over target choice. Burglar alarms were mentioned as one of the risk factors they would consider.

Nee and Taylor (1988) interviewed 50 experienced male residential burglars from three Irish prisons. The two most important considerations related to the accessibility and size of the target household (a potential indicator of the value of goods inside). Security, in the form of target hardening, was mentioned less frequently. In a follow-up study, Nee and Taylor (2000) simulated a residential environment and asked offenders (and a control group of householders) to rate five houses on the basis of their attractiveness as a target. Interestingly, the house with four high-quality alarm boxes, good quality mortise locks and spotlights divided opinion among the burglars - a third said they were very unlikely to burgle the property and half would be very likely to. 'The former group were put off by the target hardening particularly the alarms, while the latter group said the level of security advertised the fact that there was plenty to protect' (Nee and Taylor, 2000, p. 54). The least popular house to burgle was heavily overlooked by neighbouring properties but had no alarm.

Nee and Meenaghan (2006) interviewed 50 21-60 year old British experienced male burglars in two training prisons about their choice of target. The majority of those interviewed stressed the importance of layout, for example, the degree of cover available to them and their access routes. Visibility of the target household (in terms of being overseen by neighbours and passers-by) was often the most important consideration for a burglar. Many also stated that the potential profitability of the target was a key component in their assessments and, importantly, whether or not the house was occupied. Fewer offenders mentioned security: of the 50 interviewed, 8 said that they sometimes and 9 that always avoided alarms. Interestingly, over half (30) said alarms did not deter them. It may be that the alarm provided an additional cue as to resident affluence (Cromwell and Olson, 2006).

Blevins et al (2012) sent self-completion questionnaires to a sample of 1513 burglars incarcerated in Kentucky, Ohio and North Carolina. They achieved a response rate of 28 per cent. Of the 422 burglars who returned the questionnaire, about 60 per cent indicated that the presence of an alarm would deter them from carrying out a burglary in that property and this response was most prevalent among the subset of burglars who were most likely to plan out their target selection (Blevins et al, 2012, p. 4, p. 34).

A downside of prison-based research is that the respondent is at a distance from the real conditions in which they make their offending decisions. In an attempt to overcome this, research has tried to identify offenders in the community to come closer to the choices they make. In the United States, a qualitative study of 105 burglars living in the community in St Louis, identified through snowball sampling found that the vast majority of respondents said that they would avoid properties with burglar alarms (Wright and Decker, 1994). The authors quote one respondent as saying, 'If I see an alarm 
out, like I say, they usually have them outside the house, I'll leave them alone automatically' (loc, 1617). Wright and Decker, however, also found a few respondents who took an alarm to be an indicator that valuable goods could be expected, one saying, 'Alarms ... seldom are installed on residences containing little of value' (loc, 1620). Again in the United States, Cromwell and Olson $(2004,2006)$ used snowball sampling to find 30 active burglars with whom they talked extensively to find out about their decision making in relation to their offences. They also visited sites of specific burglaries to recreate the ways in which choices were made. Like Wright and Decker, they report offenders saying that they avoid properties with alarms, quoting one as saying, '... People stupid to hit a house with an alarm. Just go to one without it. That's common sense, you know' (Cromwell and Olson, 2006, p. 52). In the United Kingdom, Hearnden and Magill (2004) interviewed 82 offenders in the community identified through snowball sampling, in this case in Southern England. They found that 84 per cent rated the presence of an alarm outside a property as a deterrent.

A common feature of these studies of offender decision making is that burglars look at opportunities as a whole, the primary concern generally being with the expected returns from an offence. In choosing any specific target, the presence of an alarm was one of an array of cues that they indicated they would consider.

Buck et al (1993) undertook an extensive observational study in three neighbourhoods in Philadelphia and sought to determine the effectiveness of alarms in preventing burglary. They found that residential properties without an alarm were 2.71 times more likely to report a burglary (Buck et al, 1993, p. 504), the effects being much greater for more expensive homes.

Again in the United States, following a study of police records relating to burglaries with and without alarms in Charlotte, LeBeau and Vincent (1997) conclude that alarms do provide some protection from burglary, apparently corroborating the findings of burglars interview-based research, although they also highlight the costs of attending all burglaries, given the rate of false alarms. Among policy options to deal with this, they include: '... lowering the dispatch and response time priority for alarm calls, taking alarm calls off 911 phone lines, and requiring alarm company personnel to be on the premises of an activation before police respond' (LeBeau and Vincent, 1997, p. 306).

Budd's (1999) comprehensive analysis of burglary using 1996 and 1998 British Crime Survey data suggested that household security is strongly associated with the risk of burglary victimisation. Households ' $\ldots$ with only window locks or deadlocks reduce their risks considerably, and those with a burglar alarm, security lights or window grilles have even lower risks' (ibid, p. 13). Using logistic regression, the effectiveness of no, low and high security on burglary risk was estimated, with the findings suggesting that households with 'high security' (burglar alarm, security lights or window bars/grilles) had nearly half the risk and over seven times lower risk than those with low 
(window locks or deadlocks) and no security, respectively. Budd's work is commendable because the effect of security was gauged independently of other household features. It did not, however, differentiate between, or establish, the effects of each individual device thus providing no explicit evidence for the effectiveness of burglar alarms.

The studies described here used a variety of different methods, but each came to a similar conclusion: at least some burglars are deterred by alarms and alarmed properties therefore seem to be at reduced risk. There are a number of important caveats to be borne in mind. It is clear that burglars consider a range of cues, of which the presence of an alarm is generally one. When asked specifically to turn their attention to alarms, many will say that they are significant in their crimecommission decisions. This does indeed accord with a common sense theory of alarms: that they are effective situational measures that will tend to reduce the likelihood that those premises covered will be targeted for burglary.

The research results reported here are based on efforts to assess the effectiveness of individual security devices and specific combinations of them. This article focuses on the role of alarms in revealed choices rather than reconstructed considerations going into choices as reported by incarcerated offenders or those in the community. It also refers to conditions in England and Wales. Further work would be needed to determine whether they apply more generally.

\section{Data and Method}

The findings described here are based on analyses of multiple sweeps (1992, 1994, 1996, 2008/2009, 2009/2010, 2010/2011 and 2011/2012) of the CSEW (previously known as the British Crime Survey or BCS). The survey was first undertaken in 1982 and until 2011 administered by the Home Office. It has since been transferred to the Office for National Statistics and has the (highest) status of national data according to the UK Statistics Authority. The CSEW comprises a large-scale crime survey of adults, aged 16 and over, who reside in private accommodation in England and Wales. ${ }^{1}$ It records any crime experiences of the respondent and their households during the year before the interview together with respondents' attitudes to and perceptions of crime and the criminal justice system. The CSEW began as a survey conducted roughly once every 2 years with a sample of around 10 000-20000 respondents. Since 2001/2002 it has been conducted continuously with an annual sample size of over 40000 .

Many questions are asked, with special modules for subsets of respondents to address specific issues. Security is among those specific issues, with respondents asked about their household security devices. Importantly, burglary victims are asked about devices present at the time of the incident. In examining security 
devices, it is clearly not possible to go beyond the categories used in the CSEW questionnaire. In relation to alarms, this means that different types of system cannot be distinguished. Moreover, the range and classification of security devices covered by the survey has varied across sweeps. For example, in early sweeps internal and external security lights were not distinguished whereas they were in later ones.

The analysis presented here compares the burglary risk of those with and without burglar alarms as parts of the constellation of security devices fitted to their properties. Crucially, the questions to victims relate to the security devices in place at the time of the burglary (or first burglary that year if a repeat victim). This is important in gauging causal direction, because the experience of a burglary may prompt upgrades in security: Baker and Gray (2005) found that nearly all of the burglary victims they interviewed $(n=54)$ had made changes to their security following a break in.

In order to generate a sufficient number of cases for the purposes of analysis, CSEW sweeps asking about the same set of security devices have been combined in the analysis that follows. Thus two aggregate data sets, the 1992-1996 sweeps and the 2008/2009-2011/2012 sweeps, are analysed separately allowing comparisons between two periods of high and low burglary rates (Britton et al, 2012). In each case all possible combinations of security device have been identified, including no security.

The methodology used here to assess the marginal security effectiveness of a burglar alarm is based on and extends the Security Impact Assessment Tool (SIAT), which was originally developed to explore the protective effect of individual and combined devices against vehicle crime (see Farrell et al, 2011). It has since been applied to estimate the effectiveness of security devices against burglary (Tilley et al, 2011; Tseloni et al, 2014). The SIAT methodology produces an indication of the relative crime risk of any device or combination of devices as compared with the crime risk where there are no security devices. The SIAT calculates the Security Protection Factor (SPF). More specifically, the SPF compares the chances of victimisation for households with any particular security device (or combination of devices) with the chances of victimisation for households with no security devices. Suppose that the odds ratio of a given device (or constellation of devices) among burgled households compared with all is 0.5 , effectively indicating that the relative burglary risk among households with that device is half the overall burglary risk. Suppose also that the odds ratio of no security among burgled households compared with all is 2 , implying that households without security have twice the burglary risks than all households. The SPF would be $4(2 / 0.5)$ indicating that the said device is four times more effective against burglary as compared with no security or that the risk among households with the said device is a quarter of that for households without security.

In the following we compare SPFs for constellations of devices whose only difference comprises the presence or absence of burglar alarms. Thus marginal 
effects of burglar alarms are calculated, which forms an extension to the methodology outlined above.

\section{Results}

The SPFs against burglary victimisation among households whose security availability differs only by the presence or absence of burglar alarms across a range of otherwise identical security configurations, including no security (none), are compared in order to estimate the difference because of adding alarms.

Tables 1 and 2 present the number of households with security information in the CSEW (second column), the number of burglary with entry victims with recorded security information at the time of first burglary during the reference period of the survey (third column) and the marginal effects of adding burglar alarms (fourth column). The first column presents the security configurations including no security (none), which were available to compare across the two periods in descending order of popularity. These are window locks and door

Table 1: Number of households and number of victims of burglary with entry with security devices (individual and combinations), including none, and marginal effects of burglar alarms, CSEW 1992-1996 a

\begin{tabular}{|c|c|c|c|}
\hline \multirow[t]{2}{*}{ Security devices configuration } & \multicolumn{2}{|c|}{ Number of } & \multirow{2}{*}{$\begin{array}{c}\text { Marginal effect of } \\
\text { burglar alarm }\end{array}$} \\
\hline & $\begin{array}{l}\text { Households with } \\
\text { security information }\end{array}$ & $\begin{array}{l}\text { Victims of burglary with } \\
\text { security information }\end{array}$ & \\
\hline $\begin{array}{l}\text { Window locks and door } \\
\text { double or deadlocks }\end{array}$ & 5249 & 283 & 1.36 \\
\hline +Burglar alarm & 958 & 38 & - \\
\hline None & 4083 & 686 & 1.06 \\
\hline +Burglar alarm & 202 & 32 & - \\
\hline Door double or deadlocks & 3336 & 226 & 0.85 \\
\hline +Burglar alarm & 263 & 21 & - \\
\hline $\begin{array}{l}\text { Lights, window locks and } \\
\text { door double or deadlocks }\end{array}$ & 2543 & 86 & 1.81 \\
\hline +Burglar alarm & 1448 & 27 & - \\
\hline Window locks & 2092 & 166 & 1.46 \\
\hline +Burglar alarm & 202 & 11 & - \\
\hline $\begin{array}{l}\text { Lights and door double or } \\
\text { deadlocks }\end{array}$ & 841 & 35 & 0.95 \\
\hline +Burglar alarm & 250 & 11 & - \\
\hline Lights and window locks & 563 & 24 & 2.96 \\
\hline +Burglar alarm & 208 & 3 & - \\
\hline Lights & 551 & 31 & 1.88 \\
\hline +Burglar alarm & 67 & 2 & - \\
\hline Total & 23132 & 1796 & - \\
\hline
\end{tabular}

${ }^{\text {a }}$ Security is measured at the time of first burglary within the CSEW reference period for burglary with entry victims and at the time of interview for others. 
Table 2: Number of households and number of victims of burglary with entry with security devices (individual and combinations), including none, and marginal effects of burglar alarms, CSEW 2008/ 2009-2011/2012 a

\begin{tabular}{|c|c|c|c|}
\hline \multirow[t]{2}{*}{ Security devices configuration } & \multicolumn{2}{|c|}{ Number of } & \multirow{2}{*}{$\begin{array}{l}\text { Marginal effect of } \\
\text { burglar alarm }\end{array}$} \\
\hline & $\begin{array}{l}\text { Households } \\
\text { with security } \\
\text { information }\end{array}$ & $\begin{array}{l}\text { Victims of } \\
\text { burglary } \\
\text { with security } \\
\text { information }\end{array}$ & \\
\hline Window locks and door double or deadlocks & 5381 & 192 & 0.71 \\
\hline +Burglar alarm & 1455 & 73 & - \\
\hline $\begin{array}{l}\text { External lights on a sensor, window locks and } \\
\text { door double or deadlocks }\end{array}$ & 3307 & 43 & 0.48 \\
\hline +Burglar alarm & 1953 & 53 & - \\
\hline None & 1835 & 821 & 0.89 \\
\hline +Burglar alarm & 212 & 106 & - \\
\hline Window locks & 1765 & 120 & 0.71 \\
\hline +Burglar alarm & 272 & 26 & - \\
\hline $\begin{array}{l}\text { Window locks, internal lights on a timer, door } \\
\text { double or deadlocks and external lights on a } \\
\text { sensor }\end{array}$ & 1537 & 14 & 0.60 \\
\hline +Burglar alarm & 1589 & 24 & - \\
\hline $\begin{array}{l}\text { Internal lights on a timer, window locks and } \\
\text { door double or deadlocks }\end{array}$ & 961 & 26 & 1.10 \\
\hline +Burglar alarm & 530 & 13 & - \\
\hline Door double or deadlocks & 905 & 145 & 0.70 \\
\hline +Burglar alarm & 136 & 31 & - \\
\hline External lights on a sensor and window locks & 675 & 17 & 0.58 \\
\hline +Burglar alarm & 229 & 10 & - \\
\hline Total & 37416 & 2245 & - \\
\hline
\end{tabular}

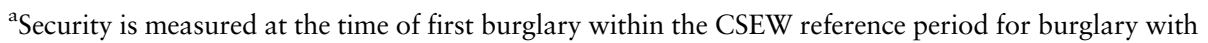
entry victims and at the time of interview for others.

double or deadlocks (WD); door double or deadlocks (D); lights, window locks and door double or deadlocks (LWD); window locks (W); lights and door double or deadlocks (LD); lights and window locks (LW); and lighting (L) in the 1992-1996 CSEW (Table 1). In the 2008/2009-2011/2012 CSEW they are window locks and door double or deadlocks (WD); external lights on a sensor, window locks and door double or deadlocks (EWD); window locks (W); external lights on a sensor, internal lights on a timer, window locks and door double or deadlocks (WIDE); internal lights on a timer, window locks and door double or deadlocks (IWD); door double or deadlocks (D); external lights on a sensor and window locks (EW) (Table 2). The configurations presented here are the ones that are comparable over time given data availability. The second and third most common household is one with no recorded security in the 1992-1996 and the 2008/2009-2011/2012 CSEW sweeps, respectively. 'No security' is not strictly comparable across the two sets. In the 1992-1996 
sweeps it refers to no alarm, lights, door double or deadlocks or window locks. However, in the 2008/2009-2011/2012 sweeps it refers to households lacking any of these devices but also lacking security chains, dummy alarm, window bars or grilles or CCTV camera. This, however, does not compromise our discussion since the focus here is the change of within sets of sweep comparisons: for each configuration with/without an alarm.

The marginal effects are the odds ratio of burglary of households with the security, including none, indicated in the first column compared with that of households with the same security except for the presence of a burglar alarm. An example of how this is calculated based on the first row of figures in Table 1 follows. The chance of being burgled for a household with window locks and door double or deadlocks was 0.0539 (283/5249), while that for a household with a burglar alarm, window locks and door double or deadlocks was 0.0397 (38/958) based on the 1992-1996 CSEW. ${ }^{2}$ The ratio of the former over the latter gives the marginal effect of burglar alarm for this configuration. In this case it is $1.36(0.0539 / 0.0397)$, indicating that the addition of a burglar alarm to window locks and door double or deadlocks offers 36 per cent higher protection against burglary with entry. Thus the marginal effects give the relative chance of being burgled of households with particular security configurations, including none, with respect to incorporating an alarm.

Figures 2 and 3 compare the marginal effects of alarms across security configurations in a succinct manner for each period under study. Figure 2 shows findings for the 1992-1996 sweeps. Figure 3 shows the findings for the 2008/2009-2011/2012 sweeps. The $\mathrm{x}$-axis presents the security configurations including no security (none), which were available in each period. The y-axis, in

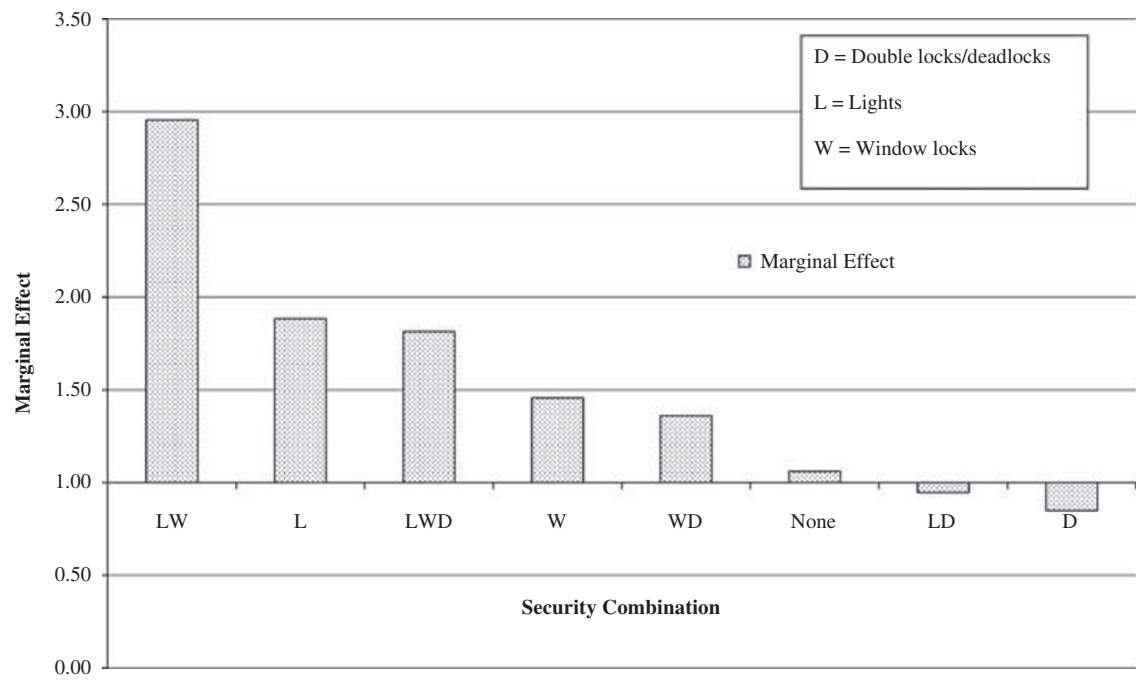

Figure 2: Marginal effects of burglar alarms for burglary with entry, CSEW sweeps 1992-1996. 
each figure shows the relative changes created by the addition of the burglar alarm with respect to burglary with entry. A score of 1 on the y-axis describes a situation where the addition of a burglar alarm makes no difference. Anything above the line comprises preventive benefits associated with the presence of an alarm. A score of 2, for example, would indicate that households with an alarm were twice as safe or suffered half the burglary risk as their counterparts with the same security devices except for the alarm. Anything below the line indicates less safety. A score of 0.5 , for example, would indicate that households with an alarm were half as safe or suffered twice the burglary risk compared with households whose security devices were the same except for the absence of an alarm.

The preponderance of below-the-line scores, notably for the recent 2008/ 2009-2011/2012 sweeps (Figure 3), came as a surprise. There was, however, one finding that did accord with expectations: The addition of an alarm to the combination of internal lights, window locks and double/deadlocks to the doors produced a slight increase in security in 2008/2009-2011/2012. For all remaining security combinations, the addition of an alarm was associated with either no change or, more often, a substantial increase in risk of burglary with entry. Thus, of eight comparisons only one suggested marginal benefits from alarms. In the remaining seven cases either there was no association with change in risk or a substantial increase in risk was associated with the presence of a burglar alarm. Unfortunately in the 2008/2009-2011/2012 sweeps the presence of an alarm was associated with greater risks of burglary with entry.

The pattern for the 1992-1996 sweeps, as shown in Figure 2, is rather different from that for the more recent sweeps. For 1992-1996 the addition of alarms to otherwise similar configurations of security device, was associated with reduced risk of burglary with entry. In that period households with lights, window locks and alarms were nearly three times more protected against burglary than those with only the first two devices. Those with lights and

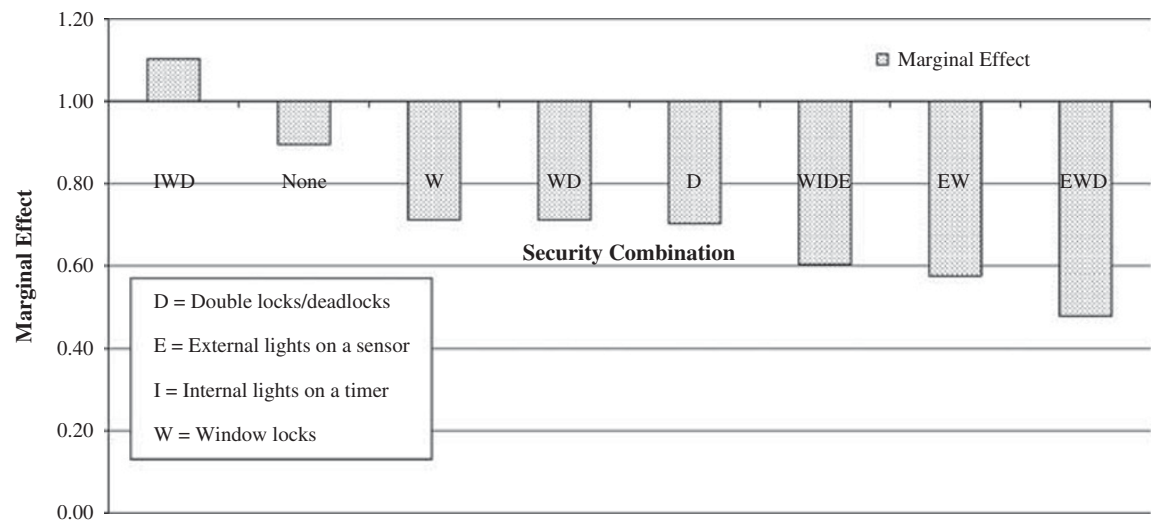

Figure 3: Marginal effects of burglar alarms for burglary with entry, CSEW sweeps 2008/20092011/2012. 
alarms were nearly twice more secured from burglary compared with households with just lights.

Comparing the patterns across the two sets of sweeps, it would appear that alarms have become of diminishing value as additions to suites of burglary prevention devices. There is also some evidence that security devices have tended to improve in sophistication and effectiveness over time and that this has contributed to the overall drop in volume crimes including vehicle-related theft and burglary (Tilley et al, 2015).

The specific findings reported here for domestic burglar alarms are anomalous, but it is important to report them, partly because if alarms really are counter-productive then as relatively expensive devices careful thought should be given to recommending their installation. It is too early yet to derive that conclusion, but in repudiating it, it would be helpful to find a satisfactory explanation for the findings reported here.

\section{Discussion}

In this section, a series of hypotheses that might explain our unexpected findings are proposed. None can be ruled out without further research, but some, we suggest, seem less plausible than others. We hope that they will stimulate further research by others to solve the conundrum.

1. Dodgy data: the consistent unexpected findings and the inconsistency with conclusions drawn by previous research suggest a hypothesis to the effect that the apparent findings are a consequence of some error in coding of the data. Repeated checks suggest, however, that there has been no such error. Moreover, the repeat counter-intuitive results across two sets of independently collected seven CSEW sweeps and the general recognition of the high quality of CSEW data make it unlikely that this is the explanation for the reported patterns. It is also possible that respondents deliberately lied in their answers to questions posed to them. This seems unlikely specifically to be the case for alarms. Other research using the same methods and data have corroborated the expected findings that more security is generally associated with lower domestic burglary risks (Tseloni et al, 2014).

2. Respondent error: Burgled respondents were asked about the security measures in place at the time of the burglary. A second hypothesis might be that respondents forgot when the alarm was installed and hence provided misleading answers: even though the alarm was fitted after the burglary they responded that it had already been there at the time of the incident (forward telescoping). On the face of it this seems unlikely. Burglaries are memorable events and it seems probable that respondents would recall that an incident led to their upgrading the security of their properties. In addition, there is no reason to believe that respondents would forward telescope the timing of 
burglar alarm installation but correctly report availability at the time of burglary of all the other security devices, which do not give counter-intuitive results. A more plausible-related hypothesis of installing a burglar alarm as a response to burglary follows.

3. Latent repeat victim: ${ }^{3}$ It is possible that the burglar alarm may have been fitted as a response to burglary victimisation that occurred before the survey's reference period and, as such, before the first burglary incident reported in the CSEW. Crime prevention initiatives developed by police and local partnerships are often tailored towards repeat victims of residential burglary, and burglar alarms are occasionally loaned or installed as part of these initiatives, alongside other target hardening measures, such as improvements to locks, doors and windows and property marking (Grove et al, 2012). This is because households already victimised and their neighbours have higher probability of subsequent victimisation, especially during a relatively short period after the first incident (Ellingworth et al, 1997; Bowers and Johnson, 2005). Therefore, in some cases the burglar alarm at the time of (first) burglary recorded by the CSEW may flag prior victimisation, and therefore disproportionately higher risk of repeat burglary victimisation during the examined period. This hypothesis seems plausible but cannot be tested with the current CSEW data because of survey reference period constraints.

4. Adaptive offender: This hypothesis has it that burglars adapt to preventive measures (Ekblom, 1997). Even if initially they are effective, over time the community of offenders finds ways of sidestepping or overcoming most measures that thereby lose their erstwhile preventive powers. Moreover, offenders may learn that only some alarms are liable significantly to increase their risks while many will not do so. This is, of course, possible. The tendency of technological developments to produce security systems that become increasingly difficult to evade makes this explanation highly unlikely. However, in practice householders may be reluctant to upgrade their systems considering their high cost. A slightly more sophisticated version of this hypothesis would have it that the police have adapted to false alarms in ways that reduce the risk increase apparently produced by alarms and that this has come to be understood by offenders who no longer assume that an alarmed dwelling presents higher risks to them. LeBeau and Vincent's finding in 1997 that the chances of an alarm leading to an arrest was 1:9.5 when all alarm calls were producing a police response suggests only limited effectiveness then. Given that one type of police adaptation to time wasted on false alarms has been no longer always to attend when an alarm sounds and to go immediately only when there is confirmation that something really is afoot, it seems likely that the risk to burglars from the police turning up while the offence is still in progress will have become much reduced. For a rational offender this would reduce reluctance to break in. 
5. Flags for target suitability: Rather than acting as a deterrent for burglary, this hypothesis has it that alarms act as flags indicating the likely presence of valuable goods for theft in a given property and hence provoke rather than inhibit the activities of burglars. In practice previous research, including that concerned with possible effects of alarms, has shown that burglars make standing decisions based on the overall prospects of quick returns or quick costs from a crime. The presence of an alarm may either be an incidental feature, associated with other indicators that burglary is likely to be rewarding, or comprise one of a range of cues that this will be the case. Except for adamant claims from some burglars that they avoid properties with alarms, this hypothesis is quite plausible although we have no data with which to test it. Moreover, it is conceivable that if an alarm is activated it may suggest to some offenders that the property is unoccupied and that they can complete a quick burglary with little chance of being disturbed.

6. Dilution/discredit/drowned out effects: Figure 1 showed the substantial growth in the numbers and proportions of properties fitted with burglar alarms in England and Wales. Moreover, there are very large numbers of apparently false alarms (although what the police define as a 'false alarm' may in the eyes of a householder comprise a successfully thwarted burglary ${ }^{4}$ ). An alarm quickly responded to when the number of alarms is small may function rather differently from an alarm slowly responded to (or not responded to at all) once alarms become mass goods, whose activation is often believed to be a nuisance rather than a cause for concern prompting reactions from neighbours and the police. This runs counter to some other security devices that may work at maximum effectiveness in an area where saturation is reached - the so-called 'tipping point' (Gladwell, 2000). This hypothesis is, thus, that alarms function as 'club' goods (Buchanan, 1965), yielding benefits only while numbers are small, but that once numbers become too large, the special benefits available only to the few are heavily diluted or drowned out by the claims for attention by the many. We lack the data to test this hypothesis.

7. Heterogeneity in systems and effects: The alarm systems patented by early pioneers, such as Pope and Tomney and the local monitoring stations established in New York in their wake, where switching alarms on was noted and where dedicated staff were on hand to respond to the activations of an alarm, is one thing. Do-it-yourself alarms fitted by local citizens, which depend on neighbours' responses and then, maybe, police attendance if genuine causes for concern are verified and there are prospects of catching the offender, are quite another. Alarms installed but not used are a third. The CSEW asks only if households have (or had) an alarm. This final hypothesis is that the apparent net negative effects mask substantial heterogeneity of systems and their consequences, wherein a substantial number of poor quality systems are associated with net negative effects, obscuring a 
significant subset where there are burglary prevention benefits. Unfortunately again we do not have the data to test this hypothesis.

\section{Conclusion}

If hypothesis 1 or 2 were correct there would be no need for the others. If they are not true, as we suggest here, then any or all of the remaining five, or perhaps an explanation not identified here, may explain the surprising patterns uncovered here.

The findings pose a puzzle for future researchers who are interested in understanding how, when and where situational measures, such as alarms do and do not work. In terms of practice and policy, if alarms are indeed generally ineffective that has implications for recommendations to citizens by the police and by insurance companies. If only some alarm systems are effective that again has implications for recommendations to citizens. If alarms are only effective if carefully monitored and responded to quickly, and if this is possible only if they are restricted to a minority of households, then this again has implications for public policy - maybe installing alarms only in repeat victims' properties known to be at high risk of further incidents, as has been undertaken in some successful burglary reduction projects (Chenery et al, 1997). If poor alarm systems are undermining the potential benefits of good alarm systems by discrediting them in the eyes of the police and offenders, then this may have implications for further regulation of their installation and use. For example, a system of paid permits and escalating fines for false alarms may help ensure that the externalities of alarms are minimised and their potential for preventive benefits increased.

Given previous research findings suggesting that they have been effective deterrents, it would be premature to conclude that domestic burglar alarms are (or have become) counter-productive and hence that their installation should no longer be encouraged. However, given the costs of installing alarms, ${ }^{5}$ their public nuisance consequences if activated when there is no crime, and the waste of public money if the police do attend without real cause, our findings suggest that more research to understand the crime reducing and crime producing contexts and mechanisms for burglar alarms is needed to inform decision making.

\section{Acknowledgements}

This work was supported by an Economic and Social Research Council Secondary Data Analysis Initiative Phase 1 grant (project REF: ESRC-SDAI (ES/K003771/1 and ES/K003771/2)). We are indebted to the project's Advisory Committee members for insightful comments and support as well as to the 
Editor and two Anonymous Reviewers of an earlier version for helpful comments and suggestions.

\section{Notes}

1 Booster samples of children aged 10-15 years old were included on an ad hoc basis in past sweeps and permanently since 2011/2012.

2 It should be highlighted that the chances of being burgled calculated from Tables 1 and 2 are not representative of the population of England and Wales. This is because security questions are asked to sub-samples of the CSEW respondents and to burglary victims who reported no more than two more serious crimes than burglary. However, the marginal effects or odds ratios, which are the focus of this discussion, cancel out any over- or underestimation resulting from the above sampling strategy.

3 We thank John Flatley, Head of the Crime Survey for England and Wales team at the ONS, for providing this insight.

4 However, offences are coded by an independent coder. The respondent is asked to describe the event, whereupon the coder allocates the code. For an attempt, there has to be some sign of attempted entry.

5 In 1985 in the United States it was estimated that US\$882000000 was spent on alarms in residential properties, but only $\$ 147393200$ on locks (Laband and Sophocleus, 1992, p. 963, pp. 973-974).

\section{References}

ACPO (2006) ACPO policy on police response to security systems, http://www.ciaalarms .co.uk/downloads/acpo_alarms2006.pdf, accessed 19 March 2014.

Baker, G. and Gray, A. (2005) Research on the Effectiveness of Police Practice in Reducing Residential Burglary Report 8: Victims of Burglary. New Zealand: Ministry of Justice.

Bennett, T. and Wright, R. (1984) Burglars on Burglary: Prevention and the Offender. Hampshire, UK: Gower Publishing Limited.

Blevins, K., Kuhns, J. and Lee, S. (2012) Understanding Decisions to Burglarize from the Offender's Perspective. Unpublished Report, http://airef.org/wp-content/uploads/2014/ 06/BurglarSurveyStudyFinalReport.pdf, accessed 19 March 2014.

Bowers, K.J. and Johnson, S.D. (2005) Domestic burglary repeats and space-time clusters: The dimensions of risk. European Journal of Criminology 2(1): 67-92.

Britton, A., Kershaw, C., Osborne, S. and Smith, K. (2012) Underlying patterns within the England and Wales crime drop. In: J. Van Dijk, A. Tseloni and G. Farrell (eds.) The International Crime Drop: New Directions in Research. Hampshire, UK: Palgrave Macmillan, pp. 159-181.

Buchanan, J. (1965) An economic theory of clubs. Economica 32(125): 1-14.

Buck, A., Hakim, S. and Rengert, G. (1993) Burglar alarms and the choice behavior of burglars: A suburban phenomenon. Journal of Criminal Justice 21(5): 497-507.

Budd, T. (1999) Burglary of Domestic Dwellings: Findings from the British Crime Survey. Home Office Statistical Bulletin 4/99. London: Home Office.

Bugg, D. (1962) Burglary Protection and Insurance Surveys. London: Stone and Cox.

Cahalane, M. (2001) Reducing false alarms has a price - So does response: Is the real price worth paying? Security Journal 14(1): 31-53.

Chenery, S., Holt, J. and Pease, K. (1997) Biting Back II: Reducing Repeat Victimisation in Huddersfield. Crime Prevention and Detection Series Paper 82. London: Home Office. 
Cromwell, P. and Olson, J. (2004) Breaking and Entering: Burglars on Burglary. Belmont, CA: Wadsworth.

Cromwell, P. and Olson, J. (2006) The reasoning burglar: Motives and decision-making strategies. In: P. Cromwell (ed.) In Their Own Words. Los Angeles, CA: Roxbury Publishing Company.

Donnelly, K. (1992) Domestic Security: The Holmes Burglar Alarm System 1853-1876. Unpublished MSc Thesis, University of Pennsylvania.

Ekblom, P. (1997) Gearing up against crime: A dynamic framework to help designers keep up with the adaptive criminal in a changing world. International Journal of Risk, Security and Crime Prevention 2(4): 249-265.

Ellingworth, D., Hope, T., Osborn, D., Trickett, A. and Pease, K. (1997) Prior victimisation and crime risk. International Journal of Risk, Security and Crime Prevention 2(3): 201-214.

Farrell, G., Tseloni, A. and Tilley, N. (2011) The effectiveness of vehicle security devices and their role in the crime drop. Criminology and Criminal Justice 11(1): 21-35.

Gladwell, M. (2000) The Tipping Point: How Little Things Can Make a Big Difference. Boston, MA: Little Brown.

Grove, L., Farrell, G., Farrington, D. and Johnson, S. (2012) Preventing Repeat Victimisation: A Systematic Review. Stockholm, Sweden: The Swedish National Council for Crime Prevention.

Hearnden, I. and Magill, C. (2004) Decision-making by House Burglars: Offenders' Perspectives. London: Home Office.

Laband, D. and Sophocleus, J. (1992) An estimate of resource expenditures on transfer activity in the United States. Quarterly Journal of Economics 107(3): 959-983.

LeBeau, J. and Vincent, K. (1997) Mapping it out: Repeat address burglary alarms. In: D. Weisburd and T. McEwan (eds.) Crime Mapping and Crime Prevention. Crime Prevention Studies, Vol. 8. Monsey, NY: Criminal Justice Press, pp. 289-310.

Litton, R. and Pease, K. (1984) Crimes and claims - The case of burglary insurance. In: R.V. Clarke and T. Hope (eds.) Coping with Burglary. Boston, MA: Kluwer-Nijhoff, pp. 201-217.

Maguire, M. and Bennett, T. (1982) Burglary in a Dwelling: The Offence, the Offender and the Victim. London: Heinemann Educational Books.

Nee, C. and Meenaghan, A. (2006) Expert decision making in burglars. British Journal of Criminology 46(5): 935-949.

Nee, C. and Taylor, M. (1988) Residential burglary in the republic of Ireland. In: M. Tomlinson, T. Varley and C. McCullagh (eds.) Whose Law and Order. Galway, Ireland: The Sociological Association of Ireland, pp. 82-103.

Nee, C. and Taylor, M. (2000) Examining burglars' target selection: Interview, experiment or ethnomethodology? Psychology, Crime \& Law 6(1): 45-59.

Papworth, J. and Collinson, P. (2005) Burglar alarms: Are they worth buying and which type is best for your home? The Guardian 10 December, http://www.theguardian.com/ money/2005/dec/10/consumernews.moneysupplement, accessed 19 March 2014.

Pope, A.R. (1853) Burglar Alarm. Patent No. 9,802. Washington DC: United States Patent Office, http://pdfpiw.uspto.gov/.piw?docid=00009802, accessed 16 April 2014.

Sampson, R. (2002) False Burglar Alarms. Problem-Oriented Guides for Police Series Guide No. 5. Washington DC: US Department of Justice.

Sampson, R. (2011) False Burglar Alarms. 2nd edn. Problem-Oriented Guides for Police Series Guide No. 5. Washington DC: US Department of Justice. 
Tilley, N., Tseloni, A. and Farrell, G. (2011) Income disparities of burglary risk. Security availability during the crime drop. British Journal of Criminology 51(2): 296-313.

Tilley, N., Farrell, G. and Clarke, R.V. (2015) Security quality and the crime drop. In: M. Andreson and G. Farrell (eds.) The Criminal Act: The Role and Influence of Routine Activity Theory. Basingstoke, UK: Palgrave Macmillan.

Tomney, J. (1895) Electric Burglar Alarm. Patent No. 540,341. Washington DC: United States Patent Office, http://uv201.com/Misc_Pages/Misc_Images/ELECTRIC_ BURGLAR_ALARM-1895.pdf, accessed 16 April 2014.

Tseloni, A., Thompson, R., Grove, L., Tilley, N. and Farrell, G. (2014) The effectiveness of burglary security devices. Security Journal. advance online publication, 30 June, doi:10.1057/sj.2014.30.

uv201.com (n.d.) The Holmes electric protective company, http:/uv201.com/Misc_Pages/ holmes_history.htm, accessed 17 April 2014.

Wright, R.T. and Decker, S.H. (1994) Burglars on the Job: Streetlife and Residential Break-Ins. Boston, MA: Northeastern University Press.

This work is licensed under a Creative Commons Attribution 3.0 Unported License. The images or other third party material in this article are included in the article's Creative Commons license, unless indicated otherwise in the credit line; if the material is not included under the Creative Commons license, users will need to obtain permission from the license holder to reproduce the material. To view a copy of this license, visit http:// creativecommons.org/licenses/by/3.0/ 